\title{
Affordable health care: What it means and how do we fix our current unaffordable system
}

\author{
Gilbert Berdine MD
}

$H_{\text {ealth }}$ care costs are rising. U.S. per capita health expenditures have increased from $\$ 133$ in 1960 to $\$ 9,508$ in $2015 .^{1}$ Some of this increase is due to price inflation, but inflation adjusted costs are still rising. A wealthier people can afford greater health care expenditures. Figure 1 shows U.S per capita health expenditures as a fraction of U.S. per capita income.

Clearly health care is a growing part of the average budget, but is health care affordable? How much health care expenditure is too great a percentage of income? These are subjective questions, so objective answers are not available. However, the fact that 6.5 million Americans chose to pay a fine rather than purchase health insurance suggests that a significant portion of Americans think the costs are too high for the value received. ${ }^{3}$
What about other countries? Figure 2 shows that other countries spend less than the United States. The U.S. far outspends every other country in the world in both per capita and percentage of GDP terms.

Does the United States receive better health care for what it spends? Life expectancy is arguably the most basic outcome measure of a health care system. Figure 3 shows that despite spending far greater amounts on health care, the U.S. is the only country illustrated that does not have a life expectancy greater than 80 . Notably, both South Korea and Chile had much lower life expectancies in 1960, spent far lower sums on health care, and have both passed the U.S. in life expectancy. Great Britain has a socialized health care system that spends less than the United States per capita and as a percentage of GDP.

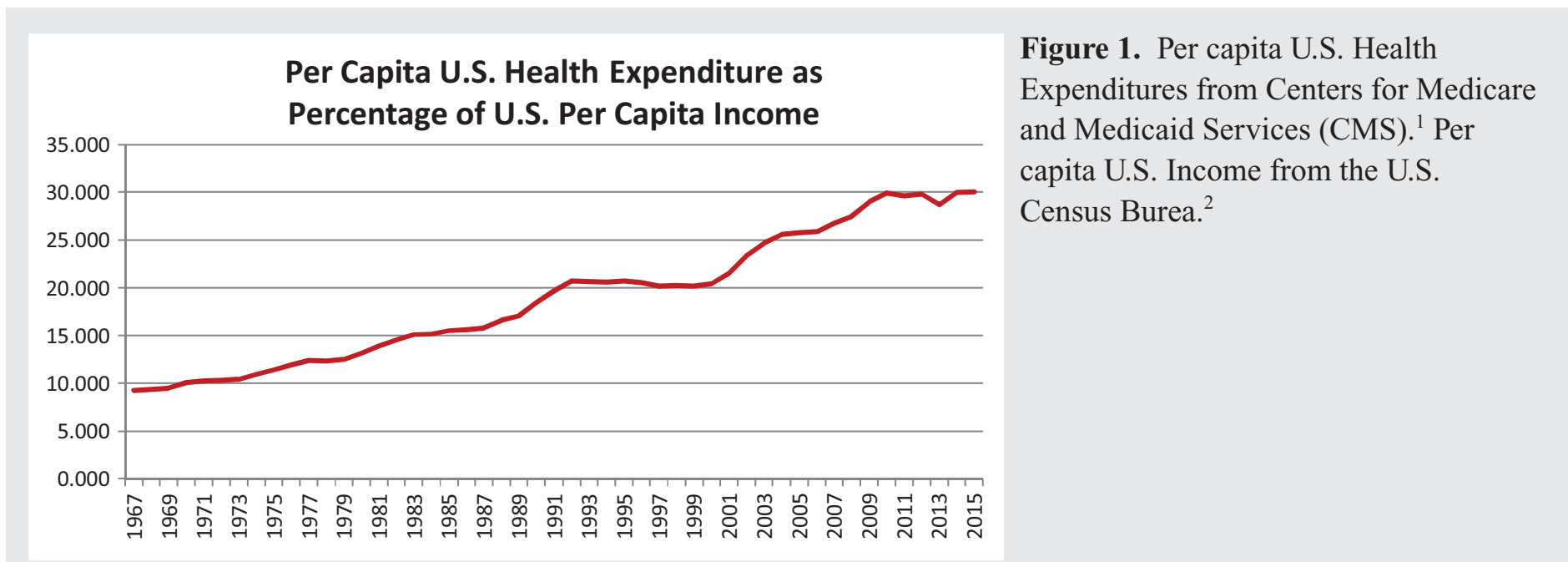

Corresponding author: Gilbert Berdine Contact Information: Gilbert.berdine@ttuhsc.edu DOI: $10.12746 /$ swrecc.v5i21.415 


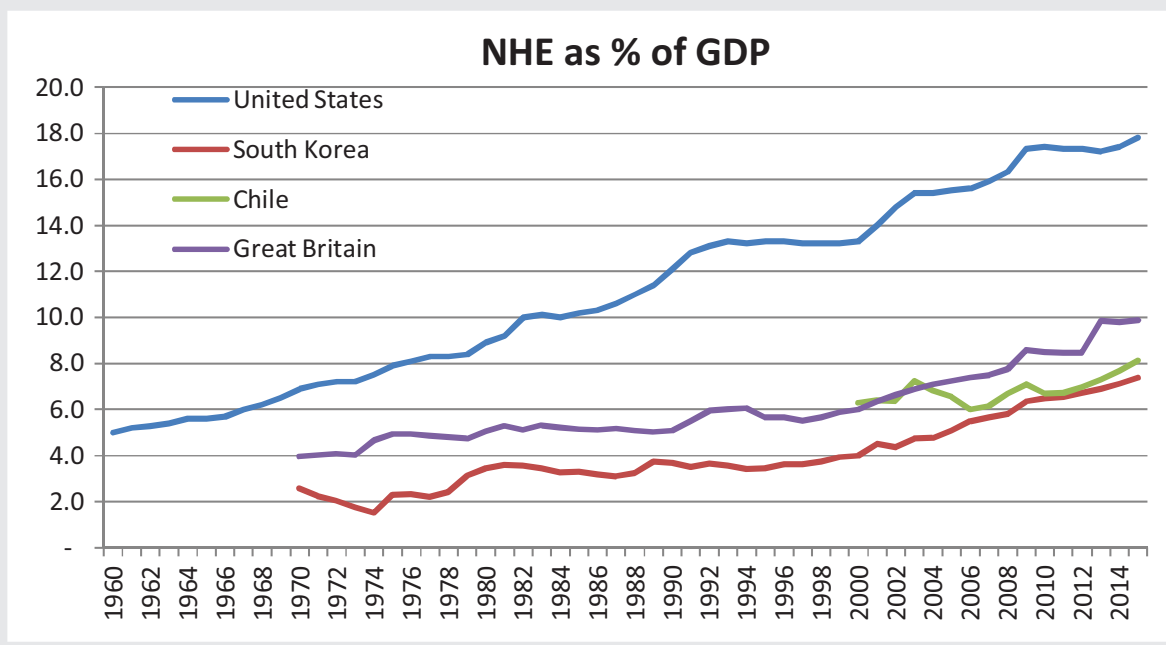

Figure 2. National health expenditures as a percentage of Gross Domestic Product (GDP). U.S. data from CMS. ${ }^{1}$ Data for other countries from the Organization for Economic Co-operation and Development (OECD). ${ }^{4}$
Despite all of its problems, the British health care system continues to deliver longer life expectancy than the United State's system.

I propose the following definition of affordable health care: Affordable health care is something that an average head of household with an average household and an average job paying an average wage can fit into his average budget yet continue to save for future dreams such as retirement. Many health care items are affordable and do not require a fix. First Aid supplies, vitamins, thermometers, and drugs such as acetaminophen are affordable and found in medicine cabinets all over the country. Clearly some elements of health care remain affordable. Why are the unaffordable elements different from the affordable ones?

Bandages are a good example of affordable health care. Nobody is claiming a human right to bandages. Nobody is demanding that employer based insurance cover bandages. Nobody is asking for a single payer for bandages. We never know when we will need a

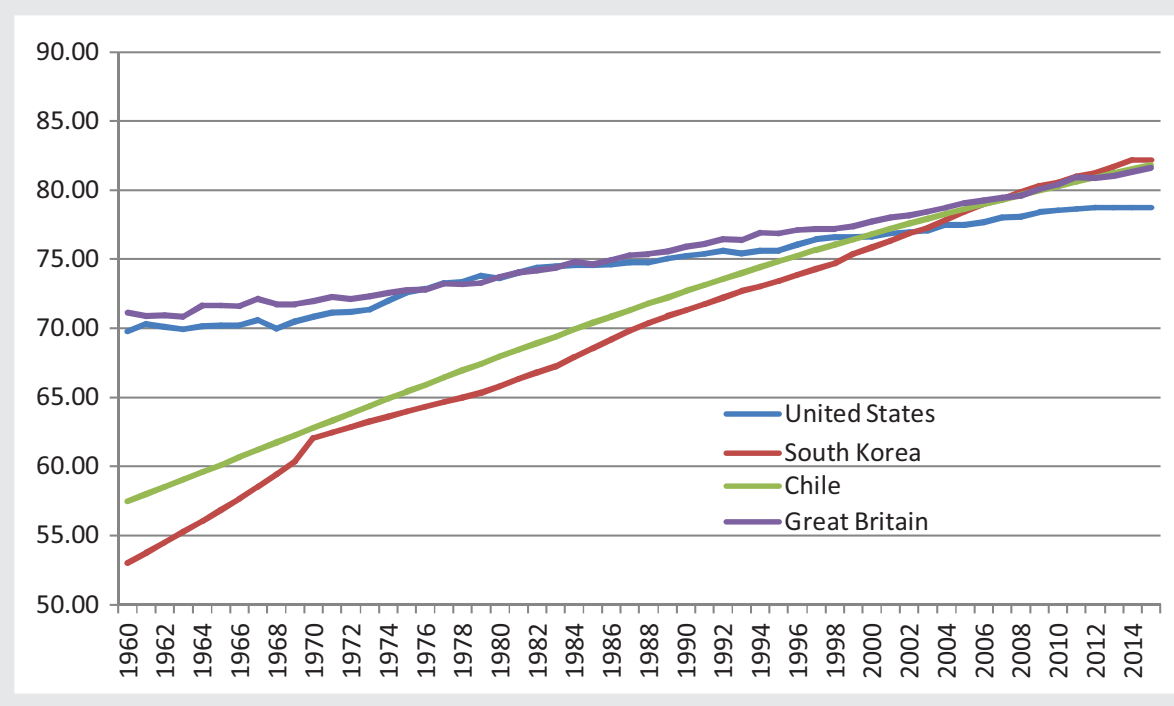

Figure 3. Life Expectancy from 1960-2015. Data from World Bank. ${ }^{5}$ 


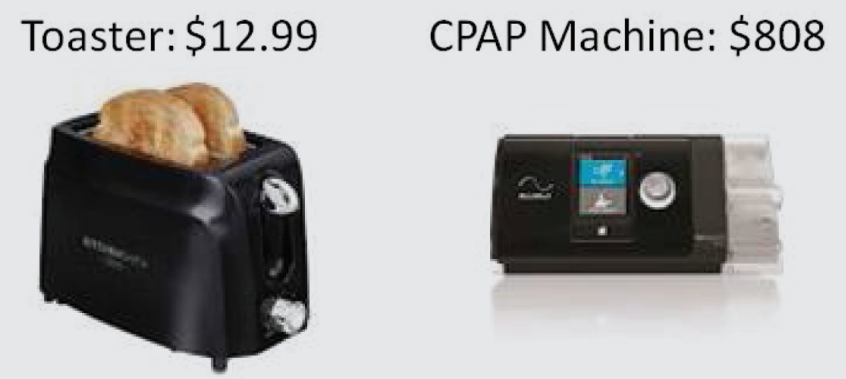

Figure 4. A comparison between a toaster and a CPAP machine.

bandage, but experience suggests that we will need them sometime, so we keep them on hand for emergencies. Why are bandages so cheap that most people keep some in the medicine cabinet? A clean rag can be used as a bandage. Pretty much everyone has access to clean rags. The FDA has not decided yet - to make the use of clean rags illegal. An expensive bandage has to offer sufficient convenience over a readily available clean rag to justify its price, limiting how much manufacturers such as Johnson \& Johnson can charge for its Band Aid brand and expect to realize sales. Robust competition leads to affordable consumer goods. Absent regulatory barriers to entry, robust competition will appear spontaneously if manufacturers try to charge outrageous prices.

Consider items such as toasters or CPAP machines. Both are items in common use by large numbers of people. Both are made from similar materials, have similar sizes, and are of similar complexity. Both are intended for daily use. Why do people pay for toasters out of pocket and want CPAP machines to be covered by insurance? A CPAP machine is not emergency equipment but is a health maintenance item. The toaster is affordable due to competition. Like some pharmaceuticals, ${ }^{6}$ CPAP machines are overly expensive due to anti-competitive government regulations. If the government did not make inexpensive and basic CPAP machines illegal, then there would be no need for requiring a spy chip to monitor "meaningful use." Government regulation has made previously affordable procedures, like thoracentesis, unaffordable. $^{7}$ The solution to unaffordable CPAP machines, pharmaceuticals, procedures, and many other health care items is not insurance, government subsidies, or government single payers, but the elimination of the government regulations that make these goods and services unaffordable. These are government failures rather than market failures.

What is the goal of affordable care? Many will argue that the goal of affordable care is to save lives. This is a misconception. Health care does not save lives. Nobody is immortal. Health care often extends lives. Extension of life is a noble goal, but at what cost? To be truly cost effective, health care must cost less than what the average patient can earn with the extended time. Otherwise, external wealth must be provided to pay for it, and the system may no longer be sustainable.

Consider a farmer who has an accident and breaks his arm. He is no longer able to harvest his crop. Without health care, he will be disabled and someone else will have to support him. With the aid of an orthopedist, his arm is restored to functional status, and he continues a long life of wealth production through farming. His current savings or future earnings expectations can pay for the services of the orthopedist. Both the orthopedist and the farmer are better off. Like many retail stores, the orthopedist can charge for services on an installment plan. Banks will voluntarily finance the procedure as long as the farmer's future earning potential is adequate to pay off the loan. To the farmer, this is no different than borrowing money to pay for his tractor. Society is better off as more food is brought to market. Everyone wins and nobody has to sacrifice to help the farmer. The care provided by the orthopedist truly paid for itself over time.

Consider a 30-year-old factory worker. He has hypertension, but he has no symptoms. There are two possible futures for this worker. He can go without care and die from a stroke or heart attack at age 50, or he can see an internist, take medication, control his hypertension, and continue working to age 70 before he retires. With even an average factory wage, his 20 years of extra earnings will easily pay for his medication and health care services (provided perverse government regulation did not make the medication and services unaffordable). This health care is affordable 
and does not require any form of cost sharing or insurance to pay for it. The factory worker will have a little less discretionary income than a healthy co-worker, but the hypertension will not prevent the factory worker from having a good life. Health care is a part of the worker's budget just like food and clothing.

The previous two scenarios were examples of health maintenance. These were ordinary problems that occur to many people. Both were easily paid for out of pocket without the need for cost sharing or insurance. What about rare events that occur to few people, but are very expensive to treat? An example would be trauma from a motor vehicle accident. These events are insurable provided the insurance is purchased before the event occurs. We will discuss an actuarially sound insurance system in Part 2. For Part 1 , we will just say that expecting insurance to cover health maintenance items such as an annual checkup makes no more sense than expecting insurance to pay the grocery bill. Health maintenance items that are needed by everyone on a regular basis should be paid for out of pocket and be part of the household budget just like food and clothing.

What about the elderly or retirees? These people are no longer working and may have no future earning potential. We will all die from chronic illness, cancer, or some other malady. The health care needs of aging and end of life are certain for everyone and should be treated as health maintenance. Each person must provide for his or her own maintenance.

Does not life insurance cover end of life? I have discussed this issue previously. ${ }^{8}$ Term life insurance is a bet on whether death will happen in a given time frame. The payout for death is part of the contract. The cost of the insurance contract increases with both the amount of the payout and the actuarial risk of death during the term of the contract. Term health insurance could be provided, if it were legal to do so, but there would be limits stipulated ahead of time about maximum benefits. Just as term life insurance does not cover suicide, term health insurance could not cover pre-existing conditions or self-inflicted illnesses. Just as the premiums for term life insurance increase with age and illness, so too would the cost of term health insurance. Just as has happened with the Affordable Care Act, people who are healthy and have low risk for illness would opt to pay for health care out of pocket rather than to share risk with people who have known illnesses with high average expectations of cost.

Would affordable health care be unavailable to the elderly and retirees? The elderly and retirees would have three possible ways to pay for health care. Savings earned earlier in life could be used, but care would be limited by the size of the savings pool. Parents could raise children who would be willing to pay for the parents' health care out of love. One could make friends in the community who would make charitable contributions for health care. Acts of goodwill that lead to loving families and communities that help one another are investments toward future needs. In such a private system, one's first responsibility is to provide for one's own health care. One's second responsibility is to assist with the health care of one's family when individual savings fell short. One's third responsibility is to assist with the health care of one's friends and neighbors. Contrast this private system with a public system where one has zero responsibility for one's own health care and $100 \%$ responsibility for the health care of complete strangers. Public systems create moral hazard. We will discuss the proper role of private charity within an affordable health care system in Part 3.

Our health care system is unaffordable, in large part, because it is focused on providing unlimited care to the elderly. The cost of health maintenance increases as we age. Eventually everyone reaches a point at which the cost of care exceeds what we have available. Unlike the farmer or the young factory worker, there is no hope that more care will pay for itself. Even if the therapy is successful and life is extended, the extended life becomes more expensive and the next health hurdle costs even more than the previous hurdle. Although limited cost sharing from young to old or rich to poor can be sustained, if the cost of care exceeds the budget of the average worker, no amount of redistribution will make this affordable.

In important ways, even the metrics by which treatments are considered successful are wrong headed 
for an affordable health care system. The usual metric by which a treatment is considered successful is survival. Survival, however, does not consider return to gainful employment. A worker who survives an illness or trauma but is unable to return to work cannot be considered an economic success. If the former worker is unable to provide basic care such as feeding and bathing, this survival has become an economic negative worse than a sudden death. This may sound harsh, but it is reality. We may want our family and friends to survive, but if they cannot provide for themselves, somebody must provide for them, and that provision will cost resources that will no longer be available to increase the standard of living for everyone else. In some cases we will voluntarily pay the price, but in other cases the cost is simply too high and cannot be paid.

Does such a private system abandon the elderly? No, the elderly receive care, but there are limits to what is offered. Consider a common end of life problem such as congestive heart failure. Diuretics and other generic medications are cheap and very effective early in therapy. A great deal of benefit can be purchased for low cost. As congestive heart failure becomes more advanced, the medications are no longer effective. Therapies such as heart valve replacements, left ventricular assist devices, and heart transplants are very expensive, offer much less benefit, and have considerable risks. ${ }^{9}$ It can be expected that enthusiasm for these expensive therapies will be much less than enthusiasm for furosemide when the patients, their families, and their friends are paying the costs rather than the public. Public payment systems ensure that provider enthusiasm exists for expensive treatments that lead only to even more expensive treatments rather than cheap and simple remedies that earn little for the providers.

In summary, the first essential step to achieving an affordable health care system is the proper use of terms such as sustainable, cost-effective, and affordable. We must separate routine health maintenance from catastrophic and unpredictable events. Health maintenance has become unaffordable due to government regulations rather than market failure. Health maintenance is properly paid for out of pocket. Each person decides how much he or she will spend in the present vs. save for the health care of old age. Each person can nurture children, friends, and neighbors to earn goodwill for their old age. Each person sets limits on what will be spent for end of life care vs. what will be the legacy to heirs. Health maintenance can be solved only by working and saving. In Part 2 we will discuss the proper role of insurance within an affordable health care system to handle outlier risks. In Part 3 we will discuss the proper role of private charity within an affordable health care system to care for those with outlier needs that are not insurable.

Keywords: Health care, costs, affordable health care

From: Department of Internal Medicine, Texas Tech University Health Sciences Center, Lubbock, TX

Submitted: $8 / 24 / 17$

Accepted: 10/2/2017

Reviewer: Mark Funderburk MBA

Conflicts of interest: none

\section{REFERENCES}

1. CMS.gov Centers for Medicare and Medicaid Services. 2016, at https:/www.cms.gov/research-statistics-data-and-systems/ statistics-trends-and-reports/nationalhealthexpenddata/ nationalhealthaccountshistorical.html

2. United States Census Bureau. 2017, at https://www.census. gov/topics/income-poverty/income/data/tables.html

3. Ballotpedia.2017, athttps://ballotpedia.org/Scott_Rasmussen $\%$ 27s_Number_of_the_Day_for_August_9,_2017

4. Healthcare Spending. OECD Data. 2016, at https://data.oecd. org/healthres/health-spending.htm

5. Life Expectancy at birth, total (years). The World Bank. 2017, at http://data.worldbank.org/indicator/SP.DYN.LE00.IN

6. Why Some Pharmaceuticals Are So Expensive. Mises Institute. 2017, at https://mises.org/blog/why-some-pharmaceuticalsare-so-expensive

7. Berdine G. Thoracentesis: a case study in the failure of cost containment. The Southwest Respiratory and Critical Care Chronicles, [S.1.], v. 5, n. 20, p. 50-53, july 2017. ISSN 23259205. Available at: http://www.pulmonarychronicles.com/ index.php/pulmonarychronicles/article/view/401/879 
8. Berdine G. Uncertainty and the Welfare Economics of Medical Care: An Austrian Rebuttal-Part 3. The Southwest Respiratory and Critical Care Chronicles, [S.1.], v. 5, n. 19, p. 25-29, may 2017. ISSN 2325-9205. Available at: http://www. pulmonarychronicles.com/index.php/pulmonarychronicles/ article/view/388/840 BA
9. Bas HD, Baser K, Nair N. Updates on management of advanced heart failure. The Southwest Respiratory and Critical Care Chronicles, [S.1.], v. 5, n. 20, p. 12-21, july 2017. ISSN 2325-9205. Available at: http://www. pulmonarychronicles.com/index.php/pulmonarychronicles/ article/view/403/887 